\title{
Infancia, ideología y lucha de clases: las prácticas culturales del Partido Comunista de la Argentina entre los niños en los años veinte
}

\author{
Childhood, ideology and class struggle: the cultural practices of the Communist \\ Party of Argentina among children in the 1920s
}

\author{
Augusto Piemonte \\ augusto.piemonte@gmail.com \\ CONICET/Laboratorio de Investigación en Ciencias \\ Humanas, Universidad de San Martín, Argentina
}

Recepción: 12 Marzo 2019

Aprobación: 31 Octubre 2019

Publicación: 13 Noviembre 2020

Cita sugerida: Piemonte, A. (2020). Infancia, ideología y lucha de clases: las prácticas culturales del Partido Comunista de la Argentina entre los niños en los años veinte. Anuario del Instituto de Historia Argentina, 20(2), e128. https://doi.org/10.24215/2314257Xe128
Resumen: A medida que el gobierno soviético se preocupaba por interceder en el desarrollo de la educación formal de sus ciudadanos, el Partido Comunista de la Argentina comenzó a plantear la necesidad de incorporar la pedagogía como parte del instrumental que debía contribuir a revolucionar la realidad social. Aunque la relación del partido con intelectuales y artistas fue analizada en varios estudios, distinta fue la suerte corrida dentro de la historiografía por las prácticas que impulsaron los comunistas en el terreno de la educación formal. Este artículo busca problematizar y analizar esta última cuestión.

Palabras clave: Partido Comunista de la Argentina, Unión Soviética, Educación, Infancia, Ideología.

\begin{abstract}
As the Soviet government was concerned about interceding in the development of formal education of Soviet citizens, the Communist Party of Argentina began to raise the need to incorporate pedagogy as one of the instruments that should contribute to revolutionize social reality. Although the party's relationship with intellectuals and artists was analyzed in several studies, the fate within historiography was different for the practices promoted by the communists in the field of formal education. This article seeks to problematize and analyze this last question.
\end{abstract}

Keywords: Communist Party of Argentina, Soviet Union, Education, Childhood, Ideology.

\section{INTRODUCCIÓN}

Promulgada en 1884 por el gobierno del Partido Autonomista Nacional presidido por Julio Argentino Roca, la ley 1420 estableció los términos para la implementación de la educación pública gratuita y obligatoria. Pese a ello, a la vuelta de siglo, en la práctica, la educación formal siguió estando o bien vedada o bien restringida para las masas populares. Esta situación motivó el surgimiento de formas educativas populares, extraoficiales, que "adquirieron especial relevancia en la integración del país: las escuelas y los cursos de los sindicatos obreros y sociedades de resistencia, los centros socialistas y anarquistas, los recreos 
infantiles, las sociedades y fraternidades, los periódicos y revistas político-ideológicas" (Corbière, 2000, s/p).

Si bien el Partido Comunista de la Argentina (PCA) buscó desde un principio concentrar su atención principalmente en el mundo del trabajo, no por ello se abstuvo de intentar una inserción importante en otros aspectos centrales de la vida social. Dado que su objetivo central era constituirse en la vanguardia que habría de guiar al proletariado en la lucha de clases para lograr su emancipación mediante la destrucción del sistema capitalista en su conjunto, la acción comunista permeó en el campo cultural. La relación del PCA con intelectuales y artistas fue -y continúa siendo- analizada en varios estudios meticulosos y muy bien documentados. ${ }^{1}$ Distinta suerte, no obstante, han corrido dentro de la historiografía las prácticas defendidas por el PCA en el terreno de la educación formal.

Durante su primera década de existencia, el PCA fue un partido que gozó de cierta autonomía respecto de la Unión Soviética. Aunque esta situación iba a verse modificada de manera radical hacia fines de 1927 tras la expulsión de José Fernando Penelón ${ }^{2}$,no por ello es menos cierto que la dirección argentina prestó atención al modo en que los bolcheviques comenzaron a tejer vínculos incipientes con los responsables de las líneas programáticas destinadas a la educación del pueblo soviético. Los bolcheviques se abstuvieron de ejercer en el campo artístico y cultural alguna influencia en los inicios de la experiencia revolucionaria. La misma posición inicial había tomado el PCA mientras daba sus primeros pasos. Es relevante, por lo tanto, atender a la parte del proyecto cultural del PCA para la clase obrera que se refiere estrictamente a la educación. Reponer lo actuado por el bolchevismo en la URSS y contrastarlo con las prácticas sostenidas por los comunistas argentinos permitirá arrojar luz sobre la relación inicial entre ambos, al tiempo que redundará en una mayor comprensión de la significación contenida en las prácticas educativas del PCA durante sus primeros años de existencia.

\section{LA EDUCACión en LA RuSia SOviÉTICA}

En tiempos del zar, la educación en todos sus niveles se encontraba reservada a la aristocracia y a una parte privilegiada de la burguesía incipiente. Entre el triunfo de la revolución y la finalización de la guerra civil la dirección soviética no manifestó intenciones de intervenir en los debates ni en las políticas educativas destinadas a los niños que recién iniciaban su escolarización. En efecto, el sistema educativo ruso funcionó en forma casi descentralizada hasta 1921. Mientras se aplicaba la Nueva Política Económica (NEP) como solución ad hoc para contrarrestar los malos resultados obtenidos en la producción y circulación de productos agrícolas, el gobierno bolchevique no sólo buscó establecer una relación más armónica con el campesinado, sino que también pretendió tender un puente con los intelligenty "sin forzarlos a respaldar la ideología oficial” (Zhu, 2000, p. 1491 [traducción nuestra]). La intelligentsia rusa se había distanciado de la revolución tras la derrota de 1905, asustada por los métodos de lucha radicales que empleaban los bolcheviques (Krupskaya, 1984, p. 159, pp. 195-196). No obstante, la respuesta de la intelligentsia fue heterogénea ante el triunfo de octubre de 1917: una parte adhirió a los bolcheviques, otra parte se unió a los blancos, en tanto que la mayor parte intentó encontrar un camino intermedio, lo que no resultaba nada sencillo en tiempos de guerra civil. Como síntesis general de la relación entre el Partido Bolchevique y la intelligentsia, el sociólogo Boris Kagarlitsky (2006, pp. 77-78) postuló que se trataba de un vínculo cooperativo aunque plagado de fricciones.

De igual modo, el fin del zarismo implicó que las escuelas superiores perdieran su autonomía, pero sin que ello implicara la exclusión de los profesores. En 1921 se puso en marcha la primera carta de escuelas superiores, por medio de la cual las influencias de docentes y estudiantes resultaban equilibradas. A cargo de la administración de las escuelas superiores se hallaba un cuerpo directivo integrado por cinco miembros, mientras que tres miembros integraban el presídium que dirigía el departamento académico. Ambas instancias contaban en su composición con representantes estudiantiles, en su mayoría miembros 
también del Komsomol. El gobierno bolchevique dedicó esfuerzos para favorecer la incorporación masiva de obreros y campesinos al sistema educativo (Zhu, 2000, p. 1492). Esta decisión fue intensificada a partir de la implementación, aprobada en el VI Congreso de la IC de 1928, de la línea de "clase contra clase".

El 2 de octubre de 1920, Lenin pronunció un discurso ante el Komsomol en el marco del III Congreso de la Unión de Juventudes Comunistas de Rusia. Sostuvo allí que era la juventud, al no sobrellevar los vicios de la educación capitalista con que cargaba su generación precedente, la que tenía la misión histórica de materializar la construcción de la sociedad comunista (Kalinin, 1953, p. 81). Según ha afirmado Lisa Kirschenbaum, "los bolcheviques, que como marxistas definían al proletariado como la fuerza móvil de la revolución, a menudo identificaban a los jóvenes con la victoria de la clase obrera. Si el proletariado comenzaba la Revolución, eran los niños de Octubre quienes la terminarían" (Kirschenbaum, 2001, p. 160 [traducción nuestra]). Como parte del proyecto dirigido a revolucionar la sociedad en su conjunto, la dirección del PCUS se volcó a forjar al nuevo ciudadano soviético en todas sus etapas biológicas. Así, en la Rusia soviética proliferaron las guarderías, los jardines de infantes y las salas de preescolar. Este interés se vio reflejado en la creación de unas 5.000 instituciones para la educación preescolar durante la década de 1920. Con anterioridad, los niños debían esperar hasta cumplir los 8 años para comenzar su instrucción formal (Valkanova, 2009, p. 211).

La educación estaba puesta al servicio de que se inculcaran los valores soviéticos al nuevo hombre y la nueva mujer. No obstante, no existió una única concepción acerca de cuál debía ser el contenido exacto de aquellos valores que se debían difundir. Dentro del Comisariado Popular de Educación (Narkompros), la posición oficial no fue homogénea, sino que cristalizaron facciones enfrentadas. La prensa y las conferencias fueron el escenario en donde expusieron sus argumentos los distintos grupos vinculados a las organizaciones educativas (Clawson, 1973, p. 689). El grupo identificado con el Partido Bolchevique planteó la necesidad de preparar a los estudiantes para la transformación material del mundo según las metas trazadas por la dirección soviética. Por su parte, un sector compuesto por educadores progresistas no-bolcheviques consideraba que la ciencia y la educación debían contribuir a formar estudiantes democráticos e independientes avezados en la crítica de las "verdades" recibidas. Aunque el Comisario del Pueblo para la Instrucción, Anatolii Lunacharskii -junto con un grupo de colaboradores, entre quienes se encontraban la vicecomisaria Nadezhda Krupskaya y el marxista heterodoxo Al'bert Petrovich Pinkevich- intentó adoptar una postura conciliatoria que sintetizaba la esencia de ambas posturas, con el paso de los años los bolcheviques que proponían la instauración de lo que percibían como un marxismo purista lograron hegemonizar la discusión cotidiana (Weiner, 1947,pp. 72-73; Teitelbaum, 1947,pp. 356-365). Entre los postulados más salientes de la dirección del Narkompros, se anularon las diferencias educativas basadas en el género. Éstas eran consideradas una rémora del pasado y debían ser suplantadas por una nueva construcción social desprejuiciada. De tal modo, tanto niños como niñas realizarían los mismos aprendizajes, orientados a favorecer la resolución práctica de situaciones cotidianas (Lodi, 2018, pp. 74-75).

El cuestionamiento a la autoridad tradicional, el incremento de oportunidades educativas, la autonomía y la iniciativa de los estudiantes llevados adelante en la Unión Soviética estaban en consonancia con las reformas educativas más liberales de Occidente. No obstante, en un contexto signado por la postergación por tiempo indeterminado de la revolución mundial, se produjo una ralentización en esta avanzada educativa a partir de la imposición de la línea "socialismo en un solo país” y la puesta en marcha del Plan Quinquenal (Mickenberg, 2010, p. 121). A medida que se iba haciendo con el control del gobierno, la facción reunida alrededor de Stalin era cada vez más propensa a la idea de constituir en lo inmediato un sistema educativo volcado a atender las necesidades de la economía (Weiner, 1947, p. 96). Los niños (futuros trabajadores) iban a ser considerados capaces de generar de manera espontánea la ruptura con el pasado y de avanzar en la construcción de una realidad nueva. Se requería de una guía preestablecida por el gobierno soviético, y a partir de entonces la intervención bolchevique en la educación pasó a ser la norma. Dando por tierra con la década de experimentaciones educativas que acababa de tener lugar, el Comité Central del Partido Comunista de la 
Unión Soviética (PCUS) decidió en 1931 que era necesario reimplantar la enseñanza tradicional. El gobierno impuso a nivel nacional programas escolares y manuales estandarizados y la celebración regular de exámenes competitivos (Ewing, 2002, p. 7). La educación -sobre todo la educación superior- recibió en la Unión Soviética especial impulso en 1932, una vez que el PCUS decretó la concreción exitosa del Plan Quinquenal aprobado en 1929 (Zhu, 2000, p. 1499). Esto le permitió al gobierno bolchevique dar por terminado el pacto de colaboración mencionado más arriba. Los institutos científicos soviéticos se convirtieron en el escenario en que los "expertos rojos" reemplazaban a los especialistas burgueses. En efecto, a pesar de la alta necesidad de cuadros técnicos planteada por la industrialización acelerada, fueron muchos los científicos e ingenieros que, habiendo cursado sus estudios antes de la revolución, recibieron acusaciones de sabotaje contrarrevolucionario (Kojevnikov, 2008, p. 130).

El escenario cultural y educativo en la Rusia soviética era taxativamente distinto del que había existido en la Rusia pre-revolucionaria. Si la población rusa analfabeta trepaba al $70 \%$ en los tiempos finales del régimen zarista, los primeros años de la revolución habían logrado reducirla al $30 \%$ y la proyección era que para 1927 sería totalmente erradicado el analfabetismo entre las personas de 18 a 35 años. ${ }^{3}$ En su camino a la liquidación definitiva del analfabetismo, no obstante, urgía que el presupuesto designado a instrucción pública registrara un sensible incremento. Los éxitos registrados en el campo cultural ruso se hicieron sentir en la prensa comunista argentina, que reprodujo un texto breve de Lunacharskii en el que se manifestaba que la cuestión de la educación debía ser de extrema importancia para la Rusia soviética. ${ }^{4}$ Las notas que se publicaban sobre los logros de la revolución en torno de la educación no iban más allá de generalidades. No parece, por ejemplo, haber un gran conocimiento de lo que ocurre a este respecto en Rusia, al punto tal que ni se mencionan las teorías de Anton Makarenko. De todos modos, el PCA buscó la forma de interesarse localmente por la educación de la clase obrera a medida que lo mismo ocurría en la Unión Soviética.

\section{Cultura y lucha de Clases en la Argentina}

El Partido Socialista Internacional, más tarde denominado Partido Comunista de la Argentina, surgió de una ruptura dentro del Partido Socialista Argentino en el mes de enero de 1918. La escisión se produjo por una fuerte confrontación entre una minoría internacionalista con la mayoría parlamentaria que comandaba la dirección socialista, la cual había abogado por la ruptura de relaciones diplomáticas con Alemania en el contexto de la Primera Guerra Mundial. Al distanciarse del Partido Socialista, los marxistas internacionalistas que fundaron el PCA no produjeron una cesura total con el pasado que conservaba como patrimonio el socialismo, sino que se apoyaron en una parte importante de la tradición socialista para determinar las tareas cotidianas del nuevo partido, para establecer algunos de sus fundamentos programáticos esenciales y para esbozar el modo de llevarlos a la práctica. Regía entre todos ellos la idea de que mediaba entre ciencia y socialismo una relación inmediata, en la que la primera conducía al segundo. ${ }^{5}$ La difusión de publicaciones periódicas y la organización de bibliotecas y escuelas populares, que se constituyó en una parte fundamental del trabajo cotidiano enarbolado por el socialismo, fue retomado en forma temprana por los comunistas. Como seala Hernán Camarero (2007), pese a existir una línea de continuidad en las formas de relacionarse con la educación formal, el contenido entre socialistas y comunistas fue esencialmente opuesto: "Los socialistas defendían la pedagogía sarmientina, la escuela pública como espacio de socialización infantil para todas las clases sociales y la escolarización de la niez obrera. La posición de los comunistas, en cambio, hizo hincapié en el combate a la enseanza 'burguesa, patriótica o religiosa' dentro de la educación pública” (p. 231). Asimismo, cabe recordar que, en un primer momento, la Revolución rusa cautivó a un nutrido grupo de anarquistas, algunos de los cuales acabaron incorporándose a las filas comunistas, portando también a cuestas sus conocimientos en el funcionamiento de las bibliotecas y escuelas libertarias (ver Suriano, 2001, pp. 217-254). 
El Centro Socialista Obrero, bajo la guía de Juan B. Justo, dio forma al despuntar el año 1897 a la Escuela Libre para Trabajadores. La educación que allí se brindaba era abierta y gratuita. La creación de escuelas formaba parte de un proyecto cultural más amplio. Como parte complementaria de la transmisión de conocimientos básicos, se fomentó la promoción de la lectura. Con la presencia de sus figuras más rutilantes -Justo, José Ingenieros, Enrique Dickmann, Leopoldo Lugones, Roberto Payró y Carlos Malagarriga-, los socialistas dieron forma a la Biblioteca Obrera el 25 de septiembre de 1897. La biblioteca reunía, para fines de la década de 1920, más de 25.000 volúmenes. Dada su magnitud y su importancia, se trasladó a la Casa del Pueblo. También a fines de siglo XIX se creó otra biblioteca socialista, a cargo del Centro Socialista Obrero de Barracas al Norte (Tripaldi, 1996). La importancia atribuida a la cultura popular condujo a que con cada conformación de un nuevo centro socialista se tornara inevitable la apertura de una biblioteca propia. Este movimiento se vio reflejado en la creación en todo el país de 397 bibliotecas socialistas para comienzos de 1932 (Corbière, 2000).

Italianos, españoles, ciudadanos de las distintas nacionalidades que componían el imperio ruso arribaron a la Argentina procedentes de las regiones más económicamente atrasadas de sus países. El índice de analfabetismo entre ellos era muy elevado. Esta situación hacía de la escuela pública una herramienta fundamental para la educación de los inmigrantes. Los socialistas bregaron por masificar la nacionalización de los extranjeros y extender entre los trabajadores y sus hijos la educación, a los fines de lograr un avance en la democratización social (Becerra, 2005, p. 100). Las escuelas obreras operaron en Buenos Aires durante la década de 1920 y comienzos de la década siguiente. Debieron funcionar, especialmente a partir del golpe de Estado de 1930 que destituyó al presidente Hipólito Yrigoyen, bajo condiciones de persecución. Las condiciones de trabajo de las escuelas obreras empeoraron fuertemente a partir de 1932, cuando se instrumentó en la Policía Federal la Sección Especial de Represión al Comunismo y un gran número de establecimientos educativos vinculados a fuerzas políticas de izquierda sufrieron la clausura y la incautación de documentos (Visacovsky, 2015, p. 33). El PCA fue ilegalizado por la dictadura de Uriburu y las repercusiones de este hecho no pudieron sino hacerse sentir en el proyecto cultural comunista, y afectaron también sus prácticas en el campo de la educación.

Mirta Lobato y Juan Suriano (2003, p. 33) retrataron de manera sintética la emergencia de una cultura de izquierda que llevaron a cabo durante las primeras décadas del siglo XX los socialistas, anarquistas, sindicalistas revolucionarios y comunistas:

Cientos de activistas y propagandistas recorrían una y otra vez el país con el objeto de crear sociedades gremiales y centros
culturales allí donde no existían; decenas de periódicos gremiales e ideológicos informaban sobre diversos aspectos del mundo
del trabajo y ponían en locución la cuestión obrera. Círculos culturales, centros de estudios y una amplia red asociativa
se complementaban con la prensa y, aunque con dificultades, intentaban construir una cultura alternativa a partir de la
organización de conferencias, escuelas, bibliotecas y actos recreativos de diversa índole. Allí, los trabajadores creaban sus
espacios de sociabilidad: efectuaban representaciones teatrales, bailaban, cantaban, se educaban, entonaban sus himnos,
desplegaban sus símbolos.

Esta militancia cultural ejercida en varios planos fue llevada adelante con ímpetu por los comunistas en Buenos Aires. En un contexto signado por la aplicación de la política del "frente único" para el movimiento comunista internacional, la sección argentina de la IC buscó hacer llegar su oferta cultural a los obreros que no estaban afiliados al partido. En este sentido, la dirigente comunista Angélica Mendoza dictó una conferencia con el título "La mujer y la misión de la biblioteca obrera" el 6 de enero de 1925 en la Biblioteca Esteban Echeverría. ${ }^{6}$ La charla estaba dirigida a todos los obreros en general y no solamente a los socios de la biblioteca organizadora. Dos meses más tarde, el Comité Central femenino organizó un curso abierto de educación marxista, que también iba a ser dictado por Angélica Mendoza (quien finalmente no pudo asistir, por lo que el dictado del curso recayó sobre Ida Bondareff, secretaria de la Sección Femenina,). ${ }^{7}$ En la Biblioteca Emilio Zola se llevaban a cabo todos los viernes lecturas colectivas de El ABC del comunismo, el difundido libro de Nikolai Bukharin y Preobrazhensky. También se planificó una excursión entre todos los obreros interesados 
al Museo Nacional de Bellas Artes para admirar las obras allí reunidas y escuchar una conferencia sobre arte a cargo de Moisés Kantor. ${ }^{8}$ Fue igualmente percibida como una herramienta de lucha de masas contra la cultura hegemónica burguesa la producción de obras cinematográficas procedentes de la Rusia Soviética, distribuidas en el país por Russ Film, que era la Sociedad Cinematográfica anexa al Comité Central Obrero de Ayuda a Rusia. ${ }^{9}$ Entre los libros que editó el PCA, junto a obras capitales de Marx, Engels, Kautsky y Zinoviev, entre otros, figuran dos de la autoría de Juan B. Justo, Estudios sobre la moneda y Teoría y práctica de la historia, lo que da cuenta de la posición conciliadora con cierto cúmulo de ideas fundamentales -y en cierto modo fundacionales- del socialismo argentino. ${ }^{10}$

Gran parte de los eventos culturales encabezados por el PCA se encontraban motivados por la necesidad de obtener los recursos materiales necesarios para mantener en funcionamiento la estructura cultural comunista. Así, por caso, el 18 de julio tuvo lugar una convocatoria a beneficio de la Biblioteca Augusto Bebel, donde se exhibieron varias películas de trasfondo social y el importante dirigente Juan Greco brindó una charla sobre la cultura en Rusia. ${ }^{11}$ Del mismo modo, interpelando a los hijos de los obreros, en la fiesta que celebró el 25 de julio de 1926 la agrupación infantil Carlos Liebknecht para los niños comunistas en el local que el PCA tenía en la calle Vera 587, se entonaron las estrofas de La Internacional, se tomó té con masas, tuvo lugar un concierto de mandolina y el cuadro del partido Aurelio Hernández brindó una conferencia sobre la educación infantil en Rusia. ${ }^{12}$

Por carecer de recursos materiales significativos, dado que pertenecía a un parido de la clase obrera y no contaba con avisos publicitarios bien pagos en sus páginas, la prensa comunista recurría a diversas fuentes de ingresos para mantener la publicación en la calle. ${ }^{13}$ Así, se diseñaron diversas estrategias, como la suscripción, las donaciones, los festivales y los empréstitos. Además de estas dificultades materiales, los comunistas debían lidiar con la persecución policial, particularmente feroz con el inicio de la llamada Década Infame inaugurada tras el golpe militar que depuso al gobierno de Yrigoyen. Esta represión creciente fue pródiga en el secuestro de ejemplares, la detención de escritores y redactores, la incautación de maquinarias de imprenta. Esta situación condujo en varias ocasiones a la clausura -a veces temporal, a veces definitiva- de las publicaciones periódicas más importantes del PCA. ${ }^{14}$

\section{EL PCA y LA PRIMERA INFANCIA}

La intervención cultural del PCA no se limitaba a la clase obrera adulta y presente, sino que aspiraba también a contrarrestar la hegemonía cultural burguesa entre los asalariados del futuro. De hecho, el mundo infantil, con la instrucción formal inicial como vehículo central, se erigía en un lugar de preeminencia en el proyecto comunista para la conformación de una cultura proletaria.

Convocada por la Federación Internacional Juvenil Comunista y el Comité Infantil del Socorro Obrero Internacional para la semana del 24 al 30 de junio de 1926, se celebró en la Argentina, aunque con algunos días de retraso, la Semana Internacional de los Niños Proletarios. Dicha campaña quedaba bajo la dirección de la Comisión de Asuntos Infantiles. A lo largo de esos siete días se realizaron actos y festivales y se distribuyeron publicaciones infantiles y juveniles. También se llevó a cabo un homenaje al líder juvenil Enrique Gernán Müller, quien había sido asesinado mientras se celebraba el VII Congreso del PCA (Comisión del Comité Central del Partido Comunista, 1947, p. 58). Müller había fundado el periódico infantil Compañerito, de aparición quincenal, cuya tirada había llegado a ascender a 20.000 ejemplares.

En una primera época Compañerito había sido mensual, con una vida breve entre 1923 y 1924, y una reaparición efímera en $1925 .{ }^{15}$ Contaba por entonces con 16 páginas, pero en su efímera segunda época, limitada a un único número que vio la luz en julio de 1932, su extensión se redujo a las 4 carillas. Solicitándolo a la administración de La Internacional, órgano del partido, ubicada en la avenida Independencia 4170, los niños de extracción proletaria podían solicitar la entrega de los ejemplares sin cargo. Por su parte, los adultos 
que se encontraran en disposición de contribuir a la difusión de los contenidos de la revista infantil podían adquirir ejemplares a precios reducidos. ${ }^{16}$

Para Lenin (2004), sin un órgano oficial no podía existir un verdadero partido revolucionario. El objetivo primordial de la prensa partidaria era contrarrestar las ideas de la clase dominante plasmadas en los medios de masas. Pero esta no era la única función de las publicaciones periódicas. Los diarios y revistas editados por el PCA tenían también, en mayor o menor medida, una dimensión pedagógica. Su propósito era contribuir a iluminar a los asalariados para ponerlos en mejores condiciones con vistas a la lucha de clases (Lobato, 2009, pp. 45-51). El mantenimiento y crecimiento de la prensa comunista se tornaba vital por su doble función: la llegada a capas no-afiliadas de trabajadores y la labor contrarrestante de la masiva prensa burguesa. El partido esperaba que la mayor cantidad de obreros comprendiera su deber de denunciar y boicotear toda venta de prensa burguesa y de difundir la prensa comunista. ${ }^{17}$ En este sentido, Compañerito se presentaba a sí mismo como "el periódico de las grandes masas de los niños obreros, campesinos y escolares pobres". ${ }^{18}$ Desde sus páginas se desafiaba el sentido nacionalista de la educación burguesa, cuestionando el adoctrinamiento conducido por los docentes en torno de la simbología contenida en la fecha patria del 25 de mayo. El patriotismo no era sino un instrumento de la burguesía para invisibilizar las diferencias sociales inherentes al capitalismo:

¿Cómo es posible que todos sean patriotas, cuando existe tanta diferencia entre unos y otros? (...) ¿Cómo es posible que la bandera que protege a los explotadores del pueblo sea el símbolo de los pobres también? (...) ¿Cómo es posible que ricos y pobres tengan la misma patria, cuando en nombre de ésta, los ricos explotan a los pobres? ${ }^{19}$

En respuesta a estos interrogantes, Compañerito concluía, siguiendo a Marx y Engels en su celebérrimo Manifiesto Comunista, que "La patria de los pobres es el mundo entero" ${ }^{20}$

En términos de tirada, durante el tiempo en que tuvo distribución, Compañerito rivalizó con la publicación más importante dedicada a los niños por la burguesía: la revista Billiken. El antagonismo entre ambas publicaciones no se limitaba a su contenido. Los obreros gráficos de Buenos Aires habían denunciado que la editorial que publicaba la revista infantil Billiken era responsable de una huelga llevada adelante por su personal contra la ley de jubilaciones. Por este motivo, Compañerito conminaba a los niños proletarios a no comprar ni leer esa publicación. ${ }^{21}$ Los niños nucleados en agrupaciones infantiles comunistas como la agrupación "Carlos Liebknecht" llamaban a realizar un boicot a las revistas del grupo editorial Atlántida (identificado con el grupo nacionalista de derecha de la Liga Patriótica Argentina y la organización patronal constituida en la Asociación del Trabajo), que entre su catálogo contaba con la revista Billiken. Coordinando su acción con la Federación Juvenil Comunista y con el Partido, los niños comunistas demostraban así madurez de conciencia al apoyar la causa del proletariado. ${ }^{22}$

En el número inaugural de su segunda época, Compañerito se había manifestado "Contra los maestros reaccionarios, contra la religión, enseñanza militar y patriotera", y llamaba a crear un "gran frente infantil" que hiciera frente a "la explotación de los niños, por pan, ropa y derecho de estudiar para todos los hijos obreros". ${ }^{23}$ Bajo los programas oficiales de educación dispuestos por la burguesía, los maestros inculcaban la ideología propia del enemigo de la clase trabajadora, procurando desconocer la existencia de situaciones patrimoniales muy distintas entre las familias a las que cada uno de ellos pertenecía. Así, la escuela se erigía en un instrumento de reproducción de las relaciones sociales de dominación, por lo que debía ser radicalmente trastocada. La única vía para establecer la igualdad residía en la liberación de los trabajadores del yugo opresor. El PCA era el único guía posible para encabezar el proceso. La educación era un ámbito de intervención atravesado por la lucha de clases en el cual debían desplegarse las fuerzas comunistas:

Los niños no pueden permanecer impasibles ante esa lucha. Deben intervenir en ella; deben formarse y capacitarse para cuando sean mayores. Ese es el objeto de las Agrupaciones Infantiles. Durante la Semana Internacional se intensifica la obra 
de los pequeños comunistas. Cada uno se convierte en propagandista y trata de atraer a otros niños. Comprenden la injusticia de la sociedad, las mentiras de la escuela, la vergüenza de la religión y quieren que todos comprendan también. ${ }^{24}$

Al promediar el año 1925, el clero conducía en la Argentina una avanzada contra la secularización de la educación argentina. La Internacional repudió el avance que intentaba el clero contra el laicismo de la enseñanza pública, denunciando "la propaganda que efectúan los curas párrocos, para obligar a los padres de familia a hacer impartir, en las escuelas del Estado, instrucción religiosa a sus hijos" ${ }^{25}$ La avanzada religiosa era percibida como una campaña que debía ser atribuida a los conservadores burgueses. ${ }^{26}$ Arturo Zapata, quien entre 1923 y 1924 había dirigido la escuela obrera de Río Cuarto, en la provincia de Córdoba, afirmaba que el proletariado debía arrancar de las manos del clero y del Estado "una de sus mejores presas": la escuela. ${ }^{27}$ Era imperativo que la educación de los hijos de obreros estuviera en manos de los mismos obreros y no de la burguesía. Esto hacía más urgente todavía que el proletariado reforzara su campaña de clase explotada, por lo que se conminaba a todos los padres obreros a estar atentos ante los peligros religiosos que podían acechar a sus hijos en la escuela.

\section{EXPRESIONES DE LA EDUCACIÓN EMANCIPADORA}

La lucha de clases encontraba expresión en todos los ámbitos de la vida social. Por tanto, el campo cultural no era impermeable a sus efectos en ninguna de sus manifestaciones. Las pretensiones de "educación neutral" que los comunistas atribuían a los anarquistas eran criticadas en duros términos, ya que resultaban una quimera. A diferencia de la "ingenuidad” anarquista, la burguesía había comprendido que la educación era un campo más en donde se disputaban los proyectos políticos. La lucha de clases era parte constitutiva de la currícula impartida en las escuelas. Al contar con el control de los resortes del Estado, la clase dominante orientaba el rumbo de la educación según sus propios intereses de clase:

La burguesía auxiliada por su organismo de opresión: el gobierno; por los piratas chauvinistas, tipo Carlés, y por los vampiros clericales, se sirve de la enseñanza para intoxicar en su provecho las mentes proletarias. Y esta es la hora en que la nefasta influencia del clericalismo se hace sentir insolente y con renovados bríos en la enseñanza, que nuestros demócratas burgueses dicen ser laica. ${ }^{28}$

El PCA denunciaba que, mientras en la Unión Soviética los bolcheviques impulsaban una obra hercúlea para sacar a sus obreros y campesinos del analfabetismo en el que se encontraban sumidos por la herencia zarista, el gobierno del radical Marcelo Torcuato de Alvear prefería dotar de un presupuesto holgado a las Fuerzas Armadas y dejar sin los recursos materiales fundamentales para garantizar el normal funcionamiento de las escuelas. ${ }^{29}$

A propósito de algunas palabras del gobernador de la provincia de Entre Ríos, que estimaba que los niños en edad escolar eran 116.000 y reconocía que asistían a clases unos 57.000, en La Internacional se preguntaban la causa de esta diferencia numérica tan importante. ${ }^{30}$ La conclusión era que si no todos los niños concurrían a la escuela no era por falta de aulas ni por la falta de maestros, sino que se debía a la imposibilidad que padecían de recibir una educación. Para reflexionar en torno a esta situación, con el patrocinio de la Agrupación Infantil Comunista "Carlos Liebknecht" se brindó la conferencia “¿Por qué los niños pobres no vamos a la escuela?”, a cargo de Orestes Ghioldi y Mika Feldman. ${ }^{31}$ Producto de las condiciones aberrantes en que sumía el capitalismo a una enorme cantidad de familias trabajadoras, los niños se encontraban muchas veces ocupados en actividades laborales. Por su parte, Compañerito dejaba en claro que bajo el régimen burgués una gran cantidad de niños sobrevivían en condiciones de extrema miseria, por lo cual no podían asistir a las escuelas. Por el contrario, bajo el régimen soviético todos los niños recibían la mejor instrucción posible. De allí se obtenía que la masificación de la educación no era compatible con el sistema capitalista y que la única garantía para la educación de los hijos de obreros residía en el triunfo del comunismo. ${ }^{32}$ 
Contrariamente, y como parte del mismo proceso educativo encarado por el gobierno nacional, la educación superior contaba con una dotación de recursos envidiables si se comparaba con las atenciones estatales recibidas por la escuela primaria. La causa de ello era evidente: a diferencia de lo que ocurría en Rusia, donde Lenin había pregonado que el desarrollo educativo y cultural de las masas era un requisito para el incremento de la productividad del trabajo, motivo por el cual las universidades abrían sus puertas a los obreros y campesinos y a sus hijos, quienes llegaban a recibir educación superior en la Argentina eran los hijos de los burgueses (1967, p. 230). En cambio, los hijos de los obreros recibían una educación primaria en condiciones críticas, y eso cuando podían efectivamente asistir a clases. En la localidad bonaerense de Dolores, un $40 \%$ de los niños en edad escolar no podía concurrir a la escuela en la Argentina a causa de la falta de vestimenta y el hambre crónica.33 El carácter obligatorio de la educación primaria se daba de bruces con la realidad capitalista. La concurrencia a clases era un paso fundamental en la vida del explotado para desarrollar las herramientas que pudieran acercarlo a su emancipación. La burguesía lo tenía presente y no cejaba en sus intentos por deteriorar y reducir la participación obrera en las escuelas públicas. ${ }^{34}$ Para el PCA, era necesario intervenir activamente en el diseño de una pedagogía contrahegemónica que pusiera a los niños en condiciones de cuestionar las desigualdades fundantes del orden capitalista.

A este respecto, La Internacional publicó un discurso pronunciado por Ida Bondareff con motivo de la reunión del Comité Central Femenino del día 24 de junio de 1923, presidido por Julia Coral, corresponsal internacional del PCA. Bondareff destacó allí la importancia de analizar la significación que guardaba la escuela en tanto "organización destinada para la instrucción y educación en el curso de la historia para ver la estrecha relación que tiene con la forma de organización económico-social”. ${ }^{35}$ Ubicaba en la Antigüedad clásica el surgimiento de la institución escolar tradicional, basada en la enseñanza de ciencias teóricas, y destacaba la ausencia absoluta de voluntad y carácter por parte del estudiante. El rol que le cabía a este último era de mera contemplación. Este sistema que condenaba a los educandos a la pasividad se había repetido en la escuela medieval. Una vez más, no había participación activa por parte de los estudiantes en su propio proceso de aprendizaje. Pero tampoco existía una concordancia entre el "bagaje escolástico" transmitido y la vida práctica, ligada a los acontecimientos cotidianos registrados en el mundo del trabajo: "El método de la enseñanza fue por el librito y el cuaderno, todo lo dominaba un espíritu formal y burocrático". ${ }^{36}$ Las necesidades inherentes al desarrollo de las fuerzas productivas en el capitalismo conllevaron la adopción de cambios sustantivos en la escuela clásica. La necesidad de técnicos, ingenieros, agrónomos y químicos tornó imperiosa la educación basada en las ciencias naturales y aplicadas. Estos conocimientos eran impartidos por la educación secundaria y la educación superior, reservadas a "los altos y medianos empleados de la industria". Las amplias masas obreras veían en inmensa medida restringida su educación a los conocimientos básicos (lectura, escritura y cálculos elementales) transmitidos por la escuela primaria. En su recorrido histórico de la educación, Bondareff concluyó que la escuela mutaba en consonancia con las necesidades de la estructura socio-económica del momento, mientras que permanecían inmutables el privilegio en términos de calidad educativa del que gozaban las clases dominantes y la condena a una formación fundada en la sumisión que recibían las clases dominadas. En este esquema, los maestros llevaban a cabo un papel crucial, ya que dedicaban ingentes esfuerzos para intensificar entre los hijos de obreros la aceptación naturalizada de su explotación y la defensa del Estado burgués.

Ante este escenario, Bondareff esbozó una contrapropuesta educativa emancipadora: la escuela unificada del trabajo. Observando la presencia de una tendencia natural del niño al movimiento, Bondareff propuso el trazado de actividades lúdicas con fines pedagógicos. El niño debía ser erigido en el sujeto central a la hora de protagonizar el proceso educativo, entendido como un proceso colectivo y solidario. Para Bondareff, se trataba de convertir la tradicional educación conservadora del statu quo en una educación transformadora del orden social. ${ }^{37}$ El disciplinamiento del niño a manos de la autoridad incuestionable del maestro lograba en el capitalismo un efecto narcótico. La escuela unificada del trabajo pretendía realzar el valor de la autoestima y la confianza de los educandos, dotándolos de un margen de autonomía que los situara en el centro de la 
escena escolar. Los hijos de obreros debían aprender a leer, escribir y resolver situaciones matemáticas, pero era fundamental, asimismo, que resistieran al patriotismo y al militarismo que, especialmente por vía de los contenidos de historia y geografía en la currícula escolar, intentaba inculcarles la burguesía.

El mismo día en que intervino Bondareff ante el Comité Central Femenino, también pronunció un discurso L. Korobizina, quien se había desempeñado como maestra en Rusia. Su intervención arroja luz acerca de la causa por la cual los debates sobre educación eran relegados en un principio a las mujeres comunistas. La razón estribaba en el hecho de que los estudiantes, además de integrar una estructura escolar, integraban también una organización familiar. La madre emergía como la encargada en el hogar de velar por la educación que recibían los niños que pertenecían a la clase obrera: "Nuestros hijos son futuros ciudadanos, futuros luchadores, y nosotras, madres, debemos prepararlos para esta lucha desde la más tierna edad" ${ }^{38}$

Quien reflexionó con más profundidad y llevó a la práctica algunas de sus ideas en torno a la cuestión de la educación de los niños fue otra camarada femenina. Habiéndose recibido de profesora de pedagogía en la Universidad Nacional de La Plata, en la provincia de Buenos Aires, Florencia Fossatti desempeñó toda su actividad profesional en la ciudad de Mendoza. Allí contribuyó a crear en 1919 el gremio Maestros Unidos, afiliado a la Federación Obrera Provincial, en el que fue designada presidenta y Angélica Mendoza (destacado cuadro futuro del PCA, expulsada en 1925 por integrar la facción "chispista") resultó nombrada secretaria general (Tarcus, 2007, pp. 219-221). Fossatti fue una gran animadora de la experiencia de la "Escuela Nueva" o "Escuela Activa". Esta corriente renovadora tuvo gran difusión entre 1927 y 1936 entre los docentes mendocinos. En 1926, con motivo de la realización del Primer Congreso Femenino Internacional, había tenido lugar la visita al país de la pedagoga italiana Maria Montessori, uno de los máximos exponentes a nivel mundial del escolanovismo. En sus fundamentos esenciales, la Escuela Nueva sintetizaba, principalmente, algunas ideas centrales de Jean-Jacques Rousseau, Henri Bergson y John Dewey. Pese a ello, las fuentes norteamericanas y europeas fueron asumidas por la pedagogía activista surgida en la Argentina no como una materia prima lista para ser traspolada en forma automática, sino como un andamiaje teórico útil para la obtención de diversas combinaciones posibles, sin que ello guardara tampoco una relación inmediata con la adscripción política de sus promotores originales (Puiggrós, 1992, p. 59). Y es que en la Argentina la corriente escolanovista surgía al calor de problemáticas específicas nacionales: "a diferencia de los sistemas de instrucción pública europeos nuestro sistema educativo carecía aún de un alcance social suficiente y la escuela debía resolver cuestiones sociales al mismo tiempo que renovaba sus formas de trabajo, accediendo a nueva literatura" (Carli, 1992, p. 126). ${ }^{39}$

Junto a Néstor Lemos y María Elena Champeau, Fossatti dio cuerpo en septiembre de 1928 al Centro de Estudios Pedagógicos Nueva Era, que para difundir sus ideas dentro del magisterio editó las revistas pedagógicas Ensayos en 1929 y Orientación de fines de 1932 a mediados de 1933. Los métodos didácticos rupturistas se vieron reflejados en su aplicación práctica y no en la selección de los contenidos programáticos (Alvarado, 2016, pp. 113-114), y pudieron ser libremente aplicados a partir de la autorización que otorgó la Dirección General de Escuelas en 1930 para la apertura de la Escuela Experimental Nueva Era, dependiente del Centro de Estudios Pedagógicos. Esta escuela proponía cambios tanto a nivel individual como social: por un lado, el niño era recuperado en su calidad de sujeto político activo, con intereses propios y márgenes de autonomía; por otra parte, favorecida por la transgresión de las normas de organización escolar tradicionales, la infancia emergía como el caldo de cultivo propicio para la gestación de una sociedad nueva basada en la solidaridad (Cattaneo, 2015, p. 99). Otra expresión del escolanovismo tuvo lugar en la ciudad de Buenos Aires desde fines de la década de 1920. No obstante, esta experiencia no alcanzó los niveles de organicidad registrados en el caso mendocino, quedando reducida a la práctica impulsada en solitario por una profesora de historia y pedagoga, la comunista Anunciada Mastelli (Cucuzza, 2017, pp. 322-323).

Así, la educación tradicional, con sus preceptos en favor del disciplinamiento clasista y la transmisión enciclopedista de conocimientos preestablecidos, se vio amenazada ante el advenimiento de esta corriente educativa alternativa. Pero fue justamente este carácter cuestionador que impugnaba el orden establecido y 
la autoridad consuetudinaria lo que llevó a la Escuela Nueva a ser acusada de "ideología bolchevique" por la derecha en el mundo occidental (Mickenberg, 2010, p. 118). Contando con el auspicio de la dirección escolar del liberal progresista Enrique Day, el escolanovismo pudo operar con cierta libertad en Mendoza hasta 1935, momento en que el conservadorismo católico se hizo con la hegemonía del gobernante Partido Demócrata Nacional (Luquez Sánchez, 2003, p. 68). El avance de la derecha y el clero, sumado a la represión sistemática contra el comunismo, marcaban el inicio del declive para el ciclo de experimentaciones en la educación formal.

De igual modo, las experiencias educativas disruptivas encontraron resistencia en el interior mismo del PCA. Aunque efectivizó su afiliación al partido recién en 1938, Fossatti adscribió al comunismo y su posición respecto de la educación formal representó la postura oficial del partido al menos hasta 1934, cuando, si bien las experimentaciones escolares se extendieron por un puñado de años más, la figura de Aníbal Ponce, rápidamente devenido emblema intelectual del partido aunque sin estar formalmente afiliado (Pasolini, 2013, p. 159), irrumpió con fuerza mediante sus posturas sobre pedagogía. Ese año, Ponce pronunció en el Colegio Libre de Estudios Superiores -en cuya fundación de 1930 había participado junto a Alejandro Korn, Carlos Ibarguren, Luis Reissig, Roberto Giusti y Narciso Laclau- uno de sus cursos más comentados: "Educación y lucha de clases". Aunque Ponce había dictado dichas lecciones en las postrimerías del "tercer período", el texto encontró difusión más amplia tras ser publicado en formato libro en 1937. Ponce criticó allí las corrientes activistas, tras advertir en ellas la encarnación de una nueva forma del contenido pedagógico burgués. Para Ponce, se había producido en julio de 1924 una ruptura en la forma de relacionarse que el Comité Central del Partido Comunista de la Unión Soviética tenía con la cultura. A partir de entonces se dejaba asentado que "para crear una literatura artística [destacado en el original] destinada a las grandes masas" se "debía romper con las tradiciones aristocráticas que hacen del arte una voluptuosidad reservada a muy pocos elegidos" (Ponce, 1974, p. 520). Entendía Ponce que la Escuela Nueva no podía ir más allá de un reformismo pequeñoburgués, dado que "Ninguna reforma pedagógica fundamental puede imponerse con anterioridad al triunfo de la clase revolucionaria que la reclama [destacado en el original], y si alguna vez parece que no es así es porque la palabra de los teóricos oculta, a sabiendas o no, las exigencias de la clase que representan" (1974, p. 434). En otras palabras, la revolución social era precondición para la revolución educativa. Resulta de este modo paradójico que el escolanovismo encontrara mejor recepción del PCA en la etapa ultraizquierdista de "lucha de case contra clase" que en la fase de alianzas interclasistas propias de los "frentes populares", justamente por ser considerado una manifestación del reformismo burgués y no un elemento transformador al servicio de la revolución obrera. Lo cierto es que quedaba ahora sí clausurado para el comunismo el fomento de prácticas ligadas a la Escuela Nueva. ${ }^{40}$

\section{CONSIDERACIONES FINALES}

El flamante PCA procuró desde temprano promover la creación de bibliotecas obreras, continuando y haciendo propias las experiencias heredadas del socialismo. Lo mismo ocurrió, en parte, en el terreno de la instrucción formal. A medida que el gobierno soviético se preocupaba por interceder en el desarrollo de la educación formal de sus ciudadanos, el PCA comenzó a plantear -sin que dejara de ocupar un lugar marginal entre las cuestiones abordadas por el partido- la necesidad de incorporar la pedagogía como parte del instrumental que debía contribuir al cambio radical de paradigmas sociales. La experiencia soviética en el plano de la educación de los nios constituyó una guía general sobre la cual el PCA debía conducir su proyecto de una cultura comunista infantil. Se trataba de un conjunto de preceptos básicos, sin mayores precisiones respecto de cómo realizar el trabajo desde un partido en formación, numéricamente muy minoritario, que operó durante toda la década de 1920 bajo las condiciones impuestas por el gobierno burgués encarnado por la Unión Cívica Radical. El PCA tomó las premisas soviéticas favorables a la ampliación de la lucha de clases en el terreno de la educación y las combinó con otras experiencias innovadoras que cuestionaban el papel 
reproductor de la escuela de algunas relaciones de dominación que tenían lugar en el aula dentro del mundo capitalista.

Amparada por el monopolio que ejercía el gobierno sobre los contenidos y las modalidades en que se eran transmitidos, la ideología burguesa era impartida con total libertad en las escuelas. Por ello, el comunismo tenía la necesidad de contrarrestar los efectos de la ideología dominante en las aulas. Las disquisiciones referidas a la pedagogía estuvieron reservadas a las mujeres del partido, dado que la educación de los hijos de obreros aparecía como una función que caía dentro de la esfera de vigilancia de sus madres. Entre los niños hijos de obreros resultaba fundamental implementar formas pedagógicas empancipadoras, constituyendo el escolanovismo una de las prácticas más innovadoras a este respecto. La prensa también ocupó un lugar destacado en el proyecto cultural comunista dirigido al público infantil. Su objetivo era contrarrestar la ideología de la clase dominante que proliferaba en los puestos de diarios y revistas con sus publicaciones especialmente dirigidas a los niños. Aunque su enorme tirada no se correspondió con un período de existencia prolongado, Compañerito desempeñó un papel central a este respecto.

\section{REFERENCIAS}

Alvarado, M. (2016). El Alegato de Florencia Fossatti: claves para una historia de las ideas pedagógicas desde una epistemología feminista. Anuario de Historia de la Educación, 17(2), 104-119.

Barrancos, D. (1996). La escena iluminada. Ciencias para trabajadores (1890-1930). Buenos Aires: Plus Ultra.

Becerra, M. (2005). ¿Fiestas patrias o fiestas socialistas? Rituales escolares e identidad socialista a principios del siglo XX. En H. Camarero y C. M. Herrera (Eds.), El Partido Socialista en Argentina. Sociedad, política e ideas a través de un siglo (97-120). Buenos Aires: Prometeo.

Camarero, H. (2007). A la conquista de la clase obrera. Los comunistas y el mundo del trabajo en la Argentina, 1920-1935. Buenos Aires: Siglo XXI.

Camarero, H. (2016). La cultura política comunista en la clase obrera argentina de entreguerras: prácticas, repertorios de organización y subjetividad militante. Anuario del Instituto de Historia Argentina Dr. Ricardo Levene, La Plata, vol. 16, 1-22.

Carli, S. (1992). El campo de la niñez. Entre el discurso de la minoridad y el discurso de la Educación Nueva. En A. Puiggrós (Dir.), Historia de la educación en la Argentina III. Escuela, democracia y orden (1916-1943) (99-160). Buenos Aires: Galerna.

Cattaneo, D. A. (2015). La arquitectura escolar moderna como campo de disputa pedagógica. Registros, $\mathrm{N}^{\circ} 12,95-114$.

Clawson, R. W. (1973). Political Socialization of Children in the USSR. Political Science Quarterly, 88(4), 684-712.

Comisión del Comité Central del Partido Comunista (1947). Esbozo de Historia del Partido Comunista de la Argentina. (Origen y desarrollo del Partido Comunista y del movimiento obrero y popular argentino). Buenos Aires: Anteo.

Corbière, E. J. (2000). La cultura obrera argentina como base de la transformación social (1890-1940). Herramienta: debate y critica marxista, $\mathrm{N}^{\circ} 12, \mathrm{~s} / \mathrm{p}$.

Cucuzza, H. R. (2017). "Desembarco de la escuela nueva en Buenos Aires: heterogéneas naves en puertos heterogéneos”. Revista Brasileira de Pesquisa (Auto) Biográfica, 2(5), 310-329.

Devés, M. A. (2014). Tras los pasos de Guillermo Facio Hebequer. Arte y política en el Buenos Aires de los años treinta. Izquierdas, $\mathrm{N}^{\circ} 19,91-111$.

Ewing, T. (2002). The Teachers of Stalinism: Policy, Practice, and Power in Soviet Schools of the 1930s. Nueva York: Peter Lang.

Jafella, S. A. (2004). Un ideario pedagógico en la educación superior. En: H. E. Biagini y A. A. Roig (Dirs.). El pensamiento alternativo en la Argentina del siglo XX. Tomo I. Identidad, utopia, integración (1900-1930). Buenos Aires: Biblos. 
Jafella, S. A. (2002). Escuela nueva en Argentina y Brasil: retrospectiva de un ideario pedagógico en la formación docente. Revista de Pedagogía, 23(67), 333-344.

Kagarlitsky, B. (2006). Los intelectuales y el Estado soviético. De 1917 al presente. Buenos Aires: Prometeo.

Kalinin, M. (1953). Sobre la educación comunista. Discursos y articulos escogidos. Buenos Aires: Anteo.

Kirschenbaum, L. A. (2001). Small Comrades. Revolutionizing Childhood in Soviet Russia, 1917-1932. Nueva York/ Londres: Routledge.

Kojevnikov, A. (2008). The Phenomenon of Soviet Science. Osiris, 23(1), 115-135.

Lobato, M. Z. (2009). La prensa obrera. Buenos Aires y Montevideo. 1890-1958. Buenos Aires: Edhasa.

Lobato, M. Z. y Suriano, J. (2003). La protesta social en la Argentina. Buenos Aires: Fondo de Cultura Económica.

Lodi, S. (2018). Nadezhda Krupskaia: uma estrela vermelha. Uberlândia/Minas Gerais: Navegando Publicações.

Luquez Sánchez, E. (2003). La experiencia de Escuela Nueva en Mendoza. Revista Historia de la Educación Latinoamericana, 5 (III), 65-83.

Massholder, A. (2014). El Partido Comunista y sus intelectuales. Pensamiento y acción de Héctor P. Agosti. Buenos Aires, Luxemburg.

Mickenberg, J. (2010). The New Generation and the New Russia: Modern Childhood as Collective Fantasy. American Quarterly, 62(1), 103-134.

Pasolini, R. (2013). Entre antifascismo y comunismo: Aníbal Ponce como ícono de una generación intelectual. En Iberoamericana, 13(52), 83-97.

Pasolini, R. (2013). Los marxistas liberales. Antifascismo y cultura comunista en la Argentina del siglo XX. Buenos Aires: Sudamericana.

Prado Acosta, L. (2018). Entre el comunismo y la industria cinematográfica argentina: los escritores argumentistas Pondal Ríos, Amorim y Yunque (1938-1941). En: S. Gayol, y S. A. Palermo (Eds.). Política y cultura de masas en la Argentina de la primera mitad del siglo XX (229-246). Los Polvorines: Universidad Nacional de General Sarmiento.

Petra, A. (2017). Intelectuales y cultura comunista. Itinerarios, problemas y debates en la Argentina de posguerra. Buenos Aires: Fondo de Cultura Económica.

Piemonte, V. A. (2015a). Lucha de facciones al interior del Partido Comunista de la Argentina hacia fines de los años veinte: la 'cuestión Penelón' y el rol de la Tercera Internacional. Cuadernos de Historia, $\mathrm{N}^{\circ} 43,31-58$.

Piemonte, V. A (2015b). "La compleja relación entre la dirección del Partido Comunista de la Argentina y la representación de la Comintern ante la ruptura de 1928”. Políticas de la Memoria. Anuario de Investigación del CeDInCI, $\mathrm{N}^{\circ} 16,236-244$.

Puiggrós, A. (1992). La educación argentina desde la reforma Saavedra-Lamas hasta el fin de la década infame. Hipótesis para la discusión. En A. Puiggrós (Dir.). Historia de la Educación en la Argentina III. Escuela, Democracia y Orden (1916-1943)(16-97). Buenos Aires: Galerna.

Saítta, S. (2001). Entre la cultura y la política: Los escritores de izquierda. En A. Cattaruzza (Dir.). Nueva Historia Argentina. Tomo 7. Crisis económica, avance del Estado e incertidumbre política (1930-1943) (383-428). Buenos Aires: Sudamericana.

Suriano, Juan (2001). Anarquistas. Cultura y politica libertaria en Buenos Aires, 1890-1910. Buenos Aires: Manantial.

Tarcus, H. (2007). Diccionario biográfico de la izquierda argentina. Buenos Aires: Emecé.

Teitelbaum, S. M. (1947). Progressive Education in the U.S.S.R.. The Journal of Educational Sociology, 20(6), 356-365

Tripaldi, N. M. (1996). La política y los centros de lectura: los socialistas fundan sus primeras bibliotecas en la ciudad de Buenos Aires 1894-1899. Revista de Biblioteconomia de Brasilia, 20(1), 41-51.

Valkanova, Y. (2009). The Passion for Educating the 'New Man': Debates about Preschooling in Soviet Russia, 1917-1925. History of Education Quarterly, 49(2), 211-221.

Visacovsky, N. (2015). Argentinos, judios y camaradas. Tras la utopia socialista. Buenos Aires: Biblos. 
Weiner, D. R. (2006). "Struggle over the Soviet Future: Science Education versus Vocationalism during the 1920s”. The Russian Review, 65(1), 72-97.

Zhu, L. (2000). "The Problem of the Intelligentsia and Radicalism in Higher Education under Stalin and Mao". Europe-Asia Studies, 52(8), 1489-1513.

\title{
FuenTES
}

Lenin, V. I. (2003). Qué hacer. Buenos Aires: Nuestra América.

Lenin, V. I. (1967). I compiti immediati del potere sovietico. En Opere complete XXVII. Febbraio-Iuglio 1918. Roma: Editori Riuniti, 211-248.

Krupskaya, N. (1984). Lenin. Su vida, su doctrina. Buenos Aires: Rescate.

Ponce, A. (1974). "Humanismo burgués y humanismo proletario (De Erasmo a Romain Rolland)". En Obras Completas. Tomo 3. Buenos Aires: Cartago, 449-553.

\section{Publicaciones periódicas}

\author{
La Correspondencia Sudamericana \\ La Internacional \\ Compañerito
}

\section{Notas}

1 Por mencionar algunos de los trabajos más recientes: Petra (2017), Massholder (2014), Saítta (2001), Devés (2014), Camarero (2016), Pasolini (2013), Prado Acosta (2018).

2 Partidario de un desarrollo más autóctono del comunismo, Penelón se enfrentó a la posición encabezada por Rodolfo Ghioldi, volcado a la internacionalización absoluta del PCA. Este conflicto concluyó en el alejamiento de Penelón y de unos 300 afiliados de extracción predominante obrera, varios de los cuales terminaron retornando al PCA.

3 "La instrucción pública en la Rusia soviética", La Internacional. Órgano del Partido Comunista (Sección Argentina de la III Internacional), 24/6/1925, año VIII, N 1063, p. 2.

4 A. V. Lunatcharski, "La cultura en Rusia", La Internacional,30-31/7/1923, año VI, N 729, p. 4.

5 "Para la mayoría de los militantes -y no sólo para los de extracción pequeño-burguesa que menudeaban en las filas socialistas- el mensaje partidario debía estar antecedido por una ilustración en materia de ciencias naturales en primer lugar, y luego de conocimientos de historia, permitiendo así introducir las tesis socialistas, lo que muchas veces fue simplemente denominado 'sociología'. Es más, no fueron pocos los que pensaban que bastaban los cursos y las conferencias con contenidos físico-naturales para que se creara el canal que comunicaría de manera casi automática los principios del socialismo, tan íntima se pensaba la relación” (Barrancos, 1996, p. 34).

6 “Editorial 'La Internacional”, La Internacional,3/1/1925, año VII, N 1002, p. 7.

7 “Curso de educación marxista”, La Internacional,21/03/1925, año VII, N 1013, p. 4.

8 “Biblioteca Emilio Zola”, La Internacional, 27/6/1925, año VIII, N 1068, p. 3.

9 "Russ Film", La Internacional, 30/8/1923, año VII, Nº 765, p. 2.

10 “Editorial 'La Internacional”, La Internacional, 23/8/1924, año VII, N 983, p. 4.

11 “Biblioteca 'Augusto Bebel'”, La Internacional, 15/7/1923, año VI, N 726, p. 2.

12 "Gran fiesta de camaradería infantil”, La Internacional, 25/7/1926, año IX, N 3130, p. 2.

13 "Empréstito pro prensa comunista”, La Internacional, 1/8/1923, año VI, N ${ }^{\circ} 740$, p. 1.

14 La Internacional enfrentó serios problemas para salir a la calle desde 1930 hasta 1936. El PCA realizó varios intentos por disponer de una prensa legal, publicando de manera sucesiva en 1932 los periódicos Bandera Roja, Mundo Obrero y Frente Único. No obstante, todas estas publicaciones fueron rápidamente identificadas con el comunismo y recayó sobre ellas la maquinaria represiva del gobierno de facto.

15 “'Compañerito'. Periódico infantil comunista”, La Internacional, 5/8/1925, año VIII, N¹100, p. 3.

16 "Prensa comunista", La Internacional,14/7/1923, año VI, N 725, p. 1. 
17 "Prensa comunista", La Internacional, 22/9/1923, año VII, Nº 785, p. 2.

18 "Nuestra reaparición", Compañerito, julio de 1932, año 1, $\mathrm{N}^{\circ} 1, \mathrm{p} .1$.

19 "El día de la patria", Compañerito, junio de 1923, año 1, N² 2, p. 2.

20 Idem.

21 Recuadro sin título, Compañerito, julio de 1924, año II, N 5, p. 6.

22 "Interesante actuación de las agrupaciones infantiles comunistas de la Argentina en un boicot", La Correspondencia Sudamericana, 30/6/1926, año I, N6, p. 2.

23 "Contra las Guerras Burguesas, Por Pan, Ropa y Escuelas para todos los niños pobres. ¡Iniciemos una gran campaña de organización!”, Compañerito, julio de 1932, año I, Nº 1, p. 1.

24 "Nuestra semana. 23 al 29 de junio de 1924", Compañerito, julio de 1924, año II, Nº 5, p. 2.

25 "En la Escuela N² 21 de la Boca”, La Internacional, 13/6/1925, año VIII, Nº 1056, p. 1.

26 "La enseñanza religiosa", La Internacional, 18/6/1925, año VIII, N 1060, p. 2.

27 "Escuelas proletarias", La Internacional, 26/9/1925, año VIII, N 1144, p. 2.

28 "El clericalismo en la enseñanza. La comandita Sagarna, Boneo y Carlés, a los pies de la iglesia”, La Internacional, 24/6/1925, año VIII, N¹063, p. 1.

29 "Mientras el ejército insume muchos millones el analfabetismo hace progresos en el país”, La Internacional, 3/7/1925, año VIII, $\mathrm{N}^{\circ} 1073$, p. 1

30 "El analfabetismo", La Internacional, 17/7/1925, año VIII, Nº 1084, p. 1.

31 “Por qué los niños pobres no vamos a la escuela?”, La Internacional, 28/3/1925, año VII, N 1014, p. 8.

32 "Los niños en Alemania”, Compañerito, julio de 1923, año 1, Nº 3, p. 4.

33 "La farsa de la enseñanza obligatoria", La Internacional, 9/10/1925, año VIII, N 1155, p. 1.

34 Como parte de este avasallamiento educativo contra los hijos de obreros, un maestro de la localidad rural de Lincoln, en la provincia de Buenos Aires, había roto varios ejemplares de Compañerito. Bajo la óptica de los comunistas, esta actitud destructiva no hacía sino confirmar el nerviosismo que generaba en la burguesía todo artefacto cultural que pretendiera desafiar la hegemonía de sus ideas. "Compañerito", La Internacional, 23/7/1926, año IX, N³128, p. 3.

35 "La educación proletaria”, La Internacional, 1/7/1923, año VI, N 714, p. 2.

36 Idem.

37 "La educación proletaria" (continuación del N 714), La Internacional, 8/7/1923, año VI, Nº 720, p. 2.

38 "La educación proletaria", La Internacional,12/7/1923, año VI, N 723, p. 2.

39 La apropiación no mecánica, sino adaptada al medio local de las ideas del escolanovismo europeo y norteamericano, también se produjo en Brasil, y a ello se debió justamente la inexistencia de un enlace orgánico entre la Escuela Nueva brasileña y aquella registrada en la experiencia argentina. Ver Jafella (2004).

40 De todas formas, las experiencias pedagógicas escolanovistas continuaron su curso, e incluso registraron un auge en la década de 1960. Véase Jafella (2002). 